\title{
Postponing the legal retirement age
}

\author{
Juan A. Lacomba • Francisco Lagos
}

Received: 11 June 2008/Accepted: 28 July 2009/Published online: 14 January 2010

(C) Spanish Economic Association and Fundación SEPI 2010

\begin{abstract}
This paper analyzes the reform of the pensionable age as an answer to the future financing problems of public pension systems. We use a two-staged model where, first, the government decides the redistribution level of the pension system and, secondly, individuals face a voting process on the legal retirement age. The results suggest that governments attempting to postpone the legal retirement age should increase the degree of intra-generational redistribution of the pension system in order to make the reform aimed at more easily achievable. More importantly, the most productive individuals could support some degree of redistribution to that aim.
\end{abstract}

Keywords Legal retirement age - Voting process - Degree of redistribution

JEL Classification H55 $\cdot$ J26

\section{Introduction}

Social Security reform is currently one of the top issues on the economic policy agenda of most industrialized countries. It is widely held that unless serious changes come about, the rise in the number of retirees relative to workers will threaten the viability of Pay-As-You-Go (PAYG) public pension systems in the long-run. With the aim of eliminating this future financial burden, important reforms are being proposed such as raising taxes, cutting pension benefits and/or delaying the retirement age (see Blondal and Scarpetta 1998, or Gruber and Wise 1997).

\footnotetext{
J. A. Lacomba (ه) - F. Lagos

Department of Economics, University of Granada, Campus la Cartuja s/n., 18011 Granada, Spain e-mail: jlacomba@ugr.es

F. Lagos

e-mail: fmlagos@ugr.es
} 
In order to achieve these reforms, the two main economic policy measures that have been considered are either to allow a greater flexibility in Social Security retirement schemes (e.g. Germany, Italy or Sweden) or to postpone the pensionable age. Indeed, this last measure is one of the policy conclusions of Maintaining Prosperity in an Ageing Society, OECD (1998): “ ... a direct way to encourage people to work longer would be to raise the pensionable age".

But delaying the retirement age may not be very popular among people. According to recent surveys, most workers tend to claim that they are happy with the current retirement age (see Cremer and Pestieau 2003) which suggests that reforms of the legal retirement age are currently a very delicate matter for governments. ${ }^{1}$

Besides, it has been demonstrated that pension systems in virtually all OECD countries in the mid-1990s made it financially unattractive to work after the age of 55, see Gruber and Wise (1997) or Blondal and Scarpetta (1998). Indeed, the general consensus in the theoretical literature related to Social Security and retirement decisions is that pension systems create enormous incentives to leave the labour force early, see Sheshinski (1978), Crawford and Lilien (1981), Kahn (1988), Fabel (1994) or Casamatta et al. (2005). ${ }^{2}$

This previous literature has mainly focused on the effects of Social Security systems on the individual retirement decision. We focus here on a different issue. This paper examines the legal retirement age. In this manner, we can emphasize the relevance of the indirect 'macro' effects of changing the pensionable age, that is, the effects on pension benefits of altering the worker/retiree ratio, the so-called dependency ratio. ${ }^{3}$

The term 'legal retirement age' usually refers to the age at which workers are eligible for benefits. There are strong incentives to stop working after this standard entitlement age. In general, there are indirect restrictions that take the form of an earnings test. Friedberg (2000) and Disney and Smith (2002) show how, above a certain amount of earnings, there is a cut in benefits (not applied to capital income). In some countries, these restrictions are direct (Portugal or Spain make entitlements to pension benefits beyond the standard age conditional on complete withdrawal from work) or frequently, individuals have to leave their current jobs to receive their pensions; see Blondal and Scarpetta (1998) or Gruber and Wise (1997). Indeed, the average retirement age in some OECD countries is very close to this standard retirement age (e.g. the United Kingdom, Portugal or Ireland). ${ }^{4}$ For these reasons,

\footnotetext{
${ }^{1}$ A survey of January 2005 for the insurance company AXA based on a sample of 9,300 people in 15 of the world's major industrialized countries finds widespread opposition among workers to increasing the retirement age limit, notably so when they are close to retirement: http://www.retirement-scope.axa.com.

${ }^{2}$ See also Galasso and Profeta (2002) for a survey of the literature on the political economy of Social Security from a more general point of view.

${ }^{3}$ Lacomba and Lagos (2006) analyze the effects of population ageing, via changes in the dependency ratio, on the preferred legal retirement age.

${ }^{4}$ When individuals are allowed early access to pension benefits, albeit with some adjustment in the amount to which they are entitled, the average retirement age is usually found between the age at which they are eligible to receive their pensions and the standard retirement age; see Blondal and Scarpetta (1998) or Samwick (1998).
} 
in this model we consider the legal retirement age to be the age at which workers must leave the labour force, that is, a mandatory retirement age.

The present article also analyzes the relationship between the legal retirement age and the redistributive nature of the pension system. We use a two-staged political economy model. This theoretical framework allows us to examine not only the role that redistribution plays in postponing the retirement age but also to identify whether the more productive individuals could also support more redistribution to that aim. As Casamatta et al. (2000) pointed out, the redistributive nature of the pension system is an integral part of the definition of the system in itself. It implies specific institutional and administrative arrangements which cannot be overturned in the short run. For this reason, the redistributive nature of the Social Security programme is chosen by the government in a first constitutional stage. On the other hand, changes in the legal retirement are currently subject to controversial debates and their future adjustments are likely to reflect the political support (or the lack of it) behind them. ${ }^{5}$ In order to reflect this popular support behind the changes in the retirement age, we consider that the legal retirement will be chosen through majority voting in a second stage by individuals differentiated at wage, being fully aware of the redistributive level and voting accordingly. ${ }^{6}$

The main findings of this study suggest that governments attempting to postpone the legal retirement age should increase the degree of intra-generational redistribution of the pension system in order to make the reform aimed at more easily achievable. ${ }^{7}$ Additionally, and concerning the government's decision, we find a counterintuitive result. The majority voting process on the legal retirement age in the second stage may have such a crucial impact that governments placing more emphasis on efficiency than on equity could have incentives to implement a pension system with some level of redistribution. The reason is the following. As the pension system becomes more redistributive the majority of the population, those with wages below the mean wage, will delay their optimal legal retirement ages. As a consequence and since the more productive individuals would prefer a higher pensionable age, an efficiency criterion could implement a pension system with a positive level of intra-generational redistribution.

In summary, and provided the expected opposition of most individuals to postponing the pensionable age, this setting suggests that in order to encourage workers to remain in the labour force, an increase in the redistributive nature of the pension system could lead to a larger social consensus.

The paper is organized as follows. Section 2 develops the model. Section 3 analyzes the (second stage) majority voting process on the legal retirement age. Section 4 studies the government's decision (first stage) regarding the redistribution

\footnotetext{
${ }^{5}$ For instance, in Switzerland in 1998 there was a referendum on a single issue, in which the voters approved a delay of 2 years in the female retirement age, from 62 to 64 , within the public pension system (see Bütler 2002).

${ }^{6}$ Other political structures used to solve bi-dimensional policy decisions in different Social Security contexts are the structural induced equilibrium (see Conde-Ruiz and Profeta 2007; Galasso 2008) or the probabilistic voting (see Profeta 2002).

${ }^{7}$ In a steady-state setting in which individuals differ by age and by wage, Lacomba and Lagos (2007) find similar results.
} 
level of the Social Security programme according to two different criteria and presents some numerical examples to illustrate the results. Section 5 contains the concluding remarks.

\section{The model}

Individuals live for two periods and they are located between a minimum and a maximum wage level, $\left[w_{-}, w^{+}\right]$. The distribution of wages has a density function $f\left(\right.$.). We assume that the mean wage, $\varpi$, is higher than the median wage, $w_{m}$. The intertemporal utility function is as follows:

$$
U(c, d)=u(c)+\beta u(d) .
$$

The utility function $u($.$) is as usual, increasing and concave: u^{\prime}()>0,. u^{\prime \prime}()<0 ;$. and $d$ are the first and second period consumptions respectively; and $\beta$ is the time preference factor which is equal to $1 /(1+r), r$ being the interest rate.

Both periods are of equal length, normalized to unity. Labour supply is assumed to be inelastic in the first period. In the second period, individuals have to work a fraction $R \in[0,1]$, chosen through a majority voting process; so $R$ can be interpreted as the legal retirement age of the system.

It should be noted that the second period consumption $d$ includes the normal consumption minus the monetary disutility of working in this second period. We assume a particular specification for this disutility, $d=x-\gamma R^{2} / 2$ where $x$ is the normal consumption in the second period and $\gamma>0$ can be interpreted as an intensity factor of the disutility of work. This quadratic specification is also used by Casamatta et al. (2005). It should also be noted that with this utility function income effects are disregarded: changes in the optimal retirement decision will only be caused by variations in the relative price of labour and consumption.

So, the first and second period consumptions for an individual of wage $w$ are:

$$
\begin{gathered}
c=w(1-\tau)-s \\
x=s(1+r)+R w(1-\tau)+(1-R) p(w),
\end{gathered}
$$

where $s \geq 0$ is the amount of savings, $\tau \in[0,1]$ is the Social Security contribution tax rate, and $p(w)$ is the constant stream of pension benefits per instant of time, collected from a Pay-As-You-Go Social Security system.

The Social Security budget constraint is

$$
\tau\left(N^{y} \int_{w_{-}}^{w^{+}} w f(w) \mathrm{d} w+N^{o} R \int_{w_{-}}^{w^{+}} w f(w) \mathrm{d} w\right)=N^{o}(1-R) \int_{w_{-}}^{w^{+}} p(w) f(w) \mathrm{d} w,
$$

where $N^{o}$ and $N^{y}=(1+n) N^{o}$ are the size of the old and young populations, respectively, $n$ is the population growth rate and $\alpha \in[0,1]$ is the intra-generational redistribution degree. Rearranging terms (4) can be written as 


$$
\tau\left(\frac{(1+n+R) \varpi}{(1-R)}\right)=\int_{w_{-}}^{w^{+}} p(w) f(w) \mathrm{d} w .
$$

From (5) the pension benefit formula $p(w)$ can be obtained:

$$
p(w)=\tau\left(\frac{(1+n+R)((1-\alpha) \varpi+\alpha w)}{1-R}\right) .
$$

As one can observe, the pension benefit formula $p(w)$ is a function of $\varpi, w$, and $\alpha .{ }^{8}$ These pension benefits are budget feasible and are equal to the total of the young population's contributions plus the old population's contributions while working divided by the old population during their retirement period. Moreover, these contributions are distributed in the following way. There is a uniform part and an earnings-related part determined by the degree of intra-generational redistribution, $\alpha$. Thus, depending on the level of $\alpha$, the type of Social Security may range from a totally uniform one $(\alpha=0)$, usually referred to as Beveridgean, to a totally actuarially fair $(\alpha=1)$, usually referred to as Bismarckian. ${ }^{9}$

\section{Voting on the legal retirement age}

Having determined the theoretical framework, let us now study how the legal retirement age is chosen through a majority voting process for a given level of redistribution of the pension system. To this end, we first derive the optimal legal retirement age of old and young individuals and secondly, we identify the median voter and determine her preferred legal retirement age. Let $R$ be the legal retirement age.

\subsection{The old}

The second period consumption is equal to

$$
d=s(1+r)+R w(1-\tau)+(1-R) p(w)-\frac{\gamma R^{2}}{2} .
$$

Therefore, substituting (6) in (7), $d$ can be rewritten as

$$
d=s(1+r)+R(w+\tau(1-\alpha)(\varpi-w))+\tau(1+n)((1-\alpha) \varpi+\alpha w)-\frac{\gamma R^{2}}{2} .
$$

Needless to say, maximizing $u(d)$ is equivalent to maximizing $d$. Consequently, the old individuals' problem can be formally represented as

\footnotetext{
${ }^{8}$ Notice that stationarity is assumed. This assumption implies that wages do not change over time and thus the pension at time $t$ depends on the same individual (and average) wages at time $t-1$ and $t$.

9 See Casamatta et al. (2000) for a classification of several OECD countries according to the redistributive nature of the Social Security system.
} 


$$
\max _{R} s(1+r)+R(w+\tau(1-\alpha)(\varpi-w))+\tau(1+n)((1-\alpha) \varpi+\alpha w)-\frac{\gamma R^{2}}{2},
$$

subject to

$$
0 \leq R \leq 1
$$

From (9) we obtain the optimal legal retirement age of an old individual $R^{o}$ with wage $w$ :

$$
R^{o}=\frac{w+\tau(1-\alpha)(\varpi-w)}{\gamma} .
$$

As in Casamatta et al. (2005), in order to assure that $R^{o} \leq 1$ for any individual, it is assumed that $\gamma \geq w^{+}$. From (10) it can be deduced that when the pension system becomes more redistributive (lower $\alpha$ ), the optimal legal retirement ages of the old individuals with wages below the mean one increase. The reason is the following. With a legal and mandatory retirement age, postponing retirement means delaying the retirement age of the whole working population, which crucially affects the pension benefits via the dependency ratio. The more redistributive the system is, the more attractive to low-wage workers the public pension will be. Thus, in order to increase the size of the Social Security system they are willing to postpone the legal retirement age and to work longer.

\subsection{The young}

The young individuals' problem can formally be represented as

$$
\max _{R, s} u(w(1-\tau)-s)+\beta u\left(s(1+r)+R w(1-\tau)+(1-R) p(w)-\frac{\gamma R^{2}}{2}\right),
$$

subject to

$$
0 \leq R \leq 1 \text { and } 0 \leq s \leq w(1-\tau) .
$$

The optimal legal retirement age of a young individual $R^{y}$ with wage $w$ is also the same as for an old individual:

$$
R^{y}=\frac{w+\tau(1-\alpha)(\varpi-w)}{\gamma} .
$$

Old and young individuals' optimal retirement ages increase with wage. ${ }^{10}$ This positive relationship between the wage and the preferred retirement age is due to the positive substitution effect of a higher wage on the retirement decision. From (11), and for individuals choosing an interior solution, we get:

$$
s^{y}=\frac{w(1-\tau)-\rho(w)}{2+r}
$$

where

\footnotetext{
10 The positive relationship between the wage and the optimal retirement age has been empirically supported by, for instance, Gruber and Wise (1997) or Samwick (1998).
} 


$$
\rho(w)=\frac{(w(1-\tau)+\tau \varpi)(w(1-\tau)-\tau \varpi)}{2 \gamma}+\tau((1+n+R)(\alpha w+(1-\alpha) \varpi)) .
$$

3.3 The voting process on the legal retirement age

Optimal legal retirement ages of young and old individuals are identical for any given wage class. These optimal ages increase with the wage. Consequently, a Condorcet winner exists. The elected legal retirement age, $R^{e}$, will be the optimal one of the individual with the median wage, $w_{m}$ :

$$
R^{e}=\frac{w_{m}+\tau(1-\alpha)\left(\varpi-w_{m}\right)}{\gamma} .
$$

By assuming that the median wage is below the mean one, (15) tells us that the larger the redistribution in pension systems is, the higher the elected legal retirement age will be. The economic intuition behind this result is the following. An increase in the redistributive nature of the system implies a higher rate of return of the pension system for the individual of median wage. As a consequence, she may have incentives to enlarge the size of the system and to rely less heavily on private savings. This can be achieved by delaying the legal retirement age which would increase the pension benefits.

This result, similar to Lacomba and Lagos (2007), contrasts with that obtained in models that study individual retirement behaviour. In those settings, it is found that a more redistributive system reduces optimal individual retirement ages. It is considered, first, that the pension system imposes an implicit tax on postponing retirement and secondly, that this implicit tax is higher, the more redistributive the system is.

For instance, Casamatta et al. (2005) analyze the optimal retirement decision in a pension system that allows for flexible retirement. They find that higher contribution rates lead to a lowering of the equilibrium retirement age. This negative relationship between the contribution rate and the optimal retirement age in Casamatta et al.'s model heavily relies on the assumption that individuals ignore the impact of their decision on the aggregate constraint. In other words, individuals consider that their retirement decision only affects the length of their working period and they ignore their influence on the dependency ratio and, therefore, on pension benefits. ${ }^{11}$

These opposite results between Casamatta et al.'s model and our setting suggest that when the reform of the pension system is a postponement of the standard age of entitlement, in order to increase the political support, the reform should be accompanied by increases in the redistributive nature of the system, since it would reduce the rejection of the majority of workers, those with wages lower than the mean one, by improving their pension benefits.

\footnotetext{
11 In Casamatta et al.'s model, this is a plausible assumption since individuals optimize their own retirement age under competitive conditions in a system that allows for flexible retirement.
} 


\section{The constitutional stage: choosing $\alpha$}

Let us now analyze how the degree of redistribution is determined at the constitutional stage. If the political parties are not ideological, that is, if they do have not preferences on the political issues, their only objective is to maximize the probability of winning the election. In other words, the classical Downsian model of political competition has a well-known theoretical result called Median Voter Theorem, which states that under some natural assumptions, two office-seeking parties will announce the same platform: the median voter's ideal policy. For this reason, we consider a Downsian criterion, where the government, by putting more emphasis on equity than on efficiency, will worry more about the median citizen. On the other hand, if parties adhere to certain ideologies and they are uncertain about the preferences of voters then they may have different criteria in equilibrium. Thus, we consider a different criterion where the government, by putting more emphasis on efficiency than on equity, will worry more about the more productive individuals. We call this last criterion the Right-wing criterion. ${ }^{12}$ As Lee (1999), we simply assume that the two criteria are possible and analyze the results under each one.

The government chooses the level of redistribution taking into account the effect on the future voting process of $R$. We can define the indirect utility function of old individuals with wage $w$ as follows

$$
\begin{aligned}
V^{o}\left(R^{e}\left(\alpha^{o}\right) ; w\right)= & u\left(s(1+r)+R^{e}\left(\alpha^{o}\right)\left(w+\tau\left(1-\alpha^{o}\right)(\varpi-w)\right)+\tau(1+n)\right. \\
& \left.\times((1-\alpha) \varpi+\alpha w)-\frac{\gamma R^{e}\left(\alpha^{o}\right)^{2}}{2}\right)
\end{aligned}
$$

and the indirect utility function of young individuals with wage $w$ as

$$
\begin{aligned}
V^{y}\left(R^{e}\left(\alpha^{y}\right) ; w\right)= & u\left(w(1-\tau)-s^{*}\left(\alpha^{y}\right)\right) \\
& +\beta u\left(s^{*}\left(\alpha^{y}\right)(1+r)+R^{e}\left(\alpha^{y}\right)\left(w+\tau\left(1-\alpha^{y}\right)(\varpi-w)\right)\right. \\
& \left.+\tau(1+n)((1-\alpha) \varpi+\alpha w)-\frac{\gamma R^{e}\left(\alpha^{y}\right)^{2}}{2}\right) .
\end{aligned}
$$

When young, if $s^{*}\left(\alpha^{y}\right)>0$ then $u(c)=u(d)$. Thus

$$
\frac{\partial V^{y}\left(R^{e}\left(\alpha^{y}\right) ; w, \alpha^{y}\right)}{\partial \alpha^{y}}=u^{\prime}(d)\left(\frac{\partial s^{*}\left(\alpha^{y}\right)}{\partial \alpha^{y}} \beta(1+r)-\frac{\partial s^{*}\left(\alpha^{y}\right)}{\partial \alpha^{y}}\right)+\beta u^{\prime}(d) \frac{\partial \psi^{y}\left(\alpha^{y}\right)}{\partial \alpha^{y}},
$$

with

$$
\psi^{y}\left(\alpha^{y}\right)=R^{e}\left(\alpha^{y}\right)\left(w+\tau\left(1-\alpha^{y}\right)(\varpi-w)\right)+\tau(1+n)((1-\alpha) \varpi+\alpha w)-\frac{\gamma R^{e}\left(\alpha^{y}\right)^{2}}{2} .
$$

Since $\beta(1+r)=1$, for any savings decision we obtain

\footnotetext{
12 See Roemer (2001) for a unified and rigorous theory of political competition between parties.
} 


$$
\frac{\partial V^{y}\left(R^{e}\left(\alpha^{y}\right) ; w, \alpha^{y}\right)}{\partial \alpha^{y}}=\beta u^{\prime}(d) \frac{\partial \psi^{y}\left(\alpha^{y}\right)}{\partial \alpha^{y}},
$$

with $\beta u^{\prime}(d)>0 .^{13}$

For old individuals we get

$$
\frac{\partial V^{o}\left(R^{e}\left(\alpha^{o}\right) ; w, \alpha^{o}\right)}{\partial \alpha^{o}}=u^{\prime}(d) \frac{\partial d\left(\alpha^{o}\right)}{\partial \alpha^{o}},
$$

with $u^{\prime}(d)>0$. Needless to say

$$
\frac{\partial \psi^{y}\left(\alpha^{y}\right)}{\partial \alpha^{y}}=\frac{\partial d\left(\alpha^{o}\right)}{\partial \alpha^{o}} .
$$

Since both $\beta$ and $u^{\prime}(d)$ are strictly positive, the sign of

$$
\frac{\partial V^{i}\left(R^{e}\left(\alpha^{i}\right) ; w, \alpha^{i}\right)}{\partial \alpha^{i}}
$$

will be equal to the sign of

$$
\frac{\partial d\left(\alpha^{o}\right)}{\partial \alpha^{o}}
$$

for $i=o, y$. Therefore, as happens with the retirement decisions, there are no differences between the preferred earnings-related pension part of old and young individuals and depending on the criterion, the following results can be stated.

\section{Proposition 1}

(1) A Downsian criterion will imply maximal redistribution.

(2) A Right-wing criterion does not always imply no redistribution.

Proof (1) Equation 23 may be written as

$$
\frac{\partial d\left(\alpha^{o}\right)}{\partial \alpha^{o}}=\varphi-\tau(1-\alpha) \vartheta+\phi
$$

with $\varphi=w_{m}(w-\bar{w})+\left(w-w_{m}\right)\left(w_{m}-\bar{w}\right), \quad \vartheta=\left(w_{m}-\bar{w}\right)(w-\bar{w})+\left(w-w_{m}\right)$ $\left(w_{m}-\bar{w}\right)$ and $\phi=\tau(1+n)(w-\bar{w})$. First, notice that (24) is single-peaked with respect to $\alpha$. Secondly, it is easy to check that since $w_{m}<\bar{w}, \vartheta>0, \varphi<0$ and $\phi<0$ for $w=w_{m}$. Therefore $\alpha^{* o}=0$ for $w=w_{m}$.

(2) We calculate (23) when there is no intra-generational redistribution:

$$
\left.\frac{\partial d\left(\alpha^{o}\right)}{\partial \alpha^{o}}\right|_{\alpha^{o}=1}=w_{m}(w-\bar{w})+\left(w-w_{m}\right)\left(w_{m}-\bar{w}\right)+\tau(1+n)(w-\bar{w}) .
$$

Thus, $\alpha^{*_{o}}<1$ for any wage distribution such that $\bar{w}>\frac{w_{m}\left(2 w^{+}-w_{m}\right)+\tau(1+n) w^{+}}{w^{+}+\tau(1+n)}$, since in these cases $\left.\frac{\partial d\left(\alpha^{o}\right)}{\partial \alpha^{o}}\right|_{\alpha^{o}=1}<0$ for any wage level. Q.E.D.

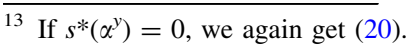


The first point of the proposition states that a government with Downsian criterion would implement a Social Security system with maximal redistribution. As mentioned earlier, changes in the redistributive nature of the pension system affect workers' lifetime income modifying their preferences for the legal retirement age. Since this criterion worries more about the median labour class, increases in the level of redistribution will have two effects: first, a longer length of the working period; and secondly and as a consequence, larger pension benefits via the dependency ratio.

The second point of the proposition states that under a Right-wing criterion, the government could choose a positive level of intra-generational redistribution in the pension system in order to maximize the utility of the most productive individuals. ${ }^{14}$ This result can be explained by the direct and indirect effects in the utility function which pull in opposite directions.

An increase in the redistribution level of the system would generate a negative direct effect on the richest individuals' welfare by reducing their pension benefits. However on the other hand, this larger redistribution will also imply a positive indirect effect by postponing the optimal legal retirement ages of the median wage workers and, consequently, the elected one. Since the optimal retirement ages of the most productive individuals are above those of the median wage workers, this delay would generate a positive indirect effect on the welfare of the richest people by reducing the distance between their optimal retirement ages and the elected one. ${ }^{15}$

Therefore, when the indirect effect outweighs the direct effect, even a government with a Right-wing criterion would implement a positive level of intra-generational redistribution in the pension system in order to encourage people to work longer.

\subsection{Numerical illustrations}

These numerical examples allow us to illustrate some of the previous analytical results. We observe how a wider gap between the mean and the median wage affects the elected retirement age. And how this age and the intra-generational degree of redistribution change because of the different political criteria. We have considered the following values for the variables of our model: wages are distributed on $\left[w_{-}, w^{+}\right]$with $w_{-}=1$ and $w^{+}=100$. In order to observe the importance of the wage distribution, we compare the results of two right-skewed distributions. They have the same median wage, $w_{m}=40$, but different mean wages. In the more disperse wage distribution, we find that $\varpi=1.65 w_{m}$. In the less disperse one, the

\footnotetext{
${ }^{14}$ It is easy to check that if the government could implement both parameters $(R, \alpha)$, the optimal redistribution degree would be no redistribution for the Right-wing criterion. But, our point is that changes in the pensionable age will only be achieved by governments with the support of a vast majority of the population. For that reason, we consider a second-best option scheme. The government chooses one parameter $(\alpha)$ and people choose the other one $(R)$.

15 If individuals were allowed to retire early (at some percentage of the legal retirement age), the level of intra-generational redistribution implemented under a Right-wing criterion would be even higher. The intuition behind is the following. While high-wage workers would still retire at the legal retirement age, low-wage workers would reduce their retirement ages which would decrease pension benefits. For this reason, an additional increase in the level of intra-generational redistribution would be needed to get a higher legal retirement age and thus, to achieve low-wage workers to delay their retirement decisions. On the other hand, if individuals were allowed to retire later, opposite results could be obtained.
} 
Table 1 Optimal legal retirement ages under Downsian (DC) and Right-wing (RC) criteria

\begin{tabular}{|c|c|c|c|c|}
\hline & \multicolumn{2}{|c|}{$\varpi=1.65 w_{m}$} & \multicolumn{2}{|c|}{$\varpi=1.5 w_{m}$} \\
\hline & $\mathrm{DC}$ & $\mathrm{RC}$ & $\mathrm{DC}$ & $\mathrm{RC}$ \\
\hline$\alpha$ & 0.00 & 0.69 & 0.00 & 1.00 \\
\hline$R^{e}$ & 0.46 & 0.42 & 0.45 & 0.40 \\
\hline$R^{*}\left(w_{-}\right)$ & 0.17 & 0.06 & 0.16 & 0.01 \\
\hline$R^{*}\left(w^{+}\right)$ & 0.91 & 0.97 & 0.90 & 1.00 \\
\hline
\end{tabular}

gap between $\varpi$ and $w_{m}$ is smaller, $\varpi=1.50 w_{m}$. The contribution tax rate is $\tau=0.25$ and the population growth rate is $n=0.02$. $^{16}$

Table 1 presents the results for the two wage distributions. The first and second columns give us the intra-generational degree of redistribution, $\alpha$, the elected legal retirement age, $R^{e}$, and the optimal ages for the poorest and the richest individuals, $R^{*}\left(w_{-}\right)$and $R^{*}\left(w^{+}\right)$, under a Downsian criterion and under a Right-wing criterion, respectively. The third and fourth columns give us the same data for a less disperse wage distribution.

Some notable insights can be obtained from the results. We observe that in the two wage distributions the elected legal retirement age under the Downsian criterion is higher than that under the Right-wing criterion. The reason is the larger redistribution associated with the Downsian criterion. It is also worth noting the comparison between the optimal retirement ages of the poorest and the richest individuals under the two political criteria. In both wage distributions, the larger the redistribution is, the closer to the elected retirement age the optimal retirement ages of the poorest and the richest individuals will be and, consequently, the lesser the disutility imposed by the mandatory retirement will be.

On the other hand, the results also confirm the second point of the aforementioned proposition. They show that if the gap between the mean and the median wage is large enough, as happens in the first two columns, the pension benefits redistribute from rich to poor even when this intra-generational degree of redistribution is imposed by the richest people. Additionally, it should be noted that the intra-generational degree of redistribution implemented with the Right-wing criterion would be $\alpha=1-(\varphi+\phi) / \tau \vartheta$, where $\phi$ depends positively on the population growth rate, $n$. This means that a decrease in this population growth rate would lead to a more redistributive scheme. The reason is the following. The lower the population growth rate, the lower the pension benefits coming from the inelastic labor force when young and thus the less the cost for high-wage workers of a higher intra-generational degree of redistribution (which delays the elected retirement age).

\section{Conclusions}

One of the main reforms undertaken to solve the viability of public pension systems is to delay the legal retirement age. In this sense, this paper suggests that

${ }^{16}$ In order to assure that $R \leq 1$ for any individual, we consider $\gamma=100$. 
governments attempting to achieve this objective should take into account the effects of modifying the redistributive nature of the pension system on workers' preferred legal retirement ages. Using a two-staged political economy model where, in the first stage, the government decides the redistribution level of the Social Security programme and, in the second one, individuals face a majority voting process on the legal retirement age, we find that increases in the intra-generational redistribution level of the pension system are related to higher elected legal retirement ages.

A more redistributive pension system will delay the preferred legal retirement ages of the majority of workers, those with wages lower than the mean wage, by improving their pension benefits. Moreover, due to the delay in the legal retirement age associated with a larger redistribution, even the richest workers could be better off since the distance between their optimal legal retirement age and the elected one would be reduced.

In summary, in order to obtain a larger social consensus, it would be appropriate to combine the delay in the pensionable age with an increase in the redistributive nature of the pension system. Even a government that put more emphasis on efficiency than on equity could be in favour of some positive level of redistribution with an aim to making a delay in the legal retirement age easier. This implies that it may not always be useful to strengthen the link between life-time contributions and pension benefits, one of the more habitual measures that is being proposed to encourage people to work longer. This measure should only be applied together with reforms aimed at increasing the flexibility of the pension system's retirement rules.

Acknowledgments We are especially grateful to Ignacio Ortuño Ortín for helpful and constructive discussions and suggestions during the elaboration of this paper. We also thank an anonymous referee for valuable comments.

\section{References}

Blondal S, Scarpetta S (1998) The retirement decision in OECD countries. OECD Working Paper AWP 1.4

Bütler M (2002) The political feasibility of increasing the retirement age: lessons from a Ballot on the female retirement age. Int Tax Public Finance 9:349-365

Casamatta G, Cremer H, Pestieau P (2000) The political economy of Social Security. Scand J Econ 102:503-522

Casamatta G, Cremer H, Pestieau P (2005) Voting on pensions with endogenous retirement age. Int Tax Public Finance 12:7-28

Conde-Ruiz JI, Profeta P (2007) The redistributive design of Social Security systems. Econ J 117:686712

Cremer H, Pestieau P (2003) The double dividend of postponing retirement. Int Tax Public Finance 10:419-434

Crawford VP, Lilien DM (1981) Social security and the retirement decision. Q J Econ 96:505-529

Disney R, Smith S (2002) The labour supply effect of the abolition of the earnings rule for older workers in the United Kingdom. Econ J 112:136-152

Fabel D (1994) The economics of pension and variable retirement Schemes. Wiley, New York

Friedberg L (2000) The labor supply effects of the Social Security earnings test. Rev Econ Stat 82:48-63

Galasso V, Profeta P (2002) The political economy of Social Security: a survey. Eur J Polit Econ 18:1-29 
Galasso V (2008) Postponing retirement: the political effect of aging. J Public Econ 92:2157-2169 Gruber J, Wise D (1997) Social Security programs and retirement around the world. University Press Chicago, Chicago

Kahn J (1988) Social Security, liquidity, and early retirement. J Public Econ 35:97-117

Lacomba JA, Lagos F (2006) Population aging and legal retirement age. J Popul Econ 19:507-519

Lacomba JA, Lagos F (2007) Political election on legal retirement Age. Soc Choice Welfare 29:1-17

Lee W (1999) Capital mobility, labor mobility, and redistributive politics. University of Manchster Discussion Paper

Profeta P (2002) Retirement and Social Security in a probabilistic voting model. Int Tax Public Finance 9:331-348

Roemer JE (2001) Political competition: theory and applications. Harvard University Press, Cambridge

Samwick A (1998) New evidence on pensions, social security, and the timing of retirement. J Public Econ 70:207-236

Sheshinski E (1978) A model of social security and retirement decisions. J Public Econ 10:337-360 